\title{
OR-30
}

\section{INVESTIGATION OF THE HYDRODYNAMICS OF MIXING TWO TECHNOLOGICAL MEDIA WITH A SMALL-SIZED AGITATOR}

\author{
A. P. Khomyakov, S. V. Mordanov, D. R. Naskina, I. S. Kovalev, T. V. Khomyakova \\ Ural Federal University named after the first President of Russia B. N. Yeltsin, \\ 19 Mira St., Yekaterinburg, 620002, Russia. \\ E-mail: dilay1909@mail.ru
}

\begin{abstract}
The existing precipitation plant uses a cascade of three reactors connected in series, each with a mixing device and a heat exchanger. Numerical simulation of mixing fluid dynamics was carried out using the ANSYS Fluent CFD code with a standard k-epsilon turbulence model and a mixture model. The study considered a two-phase model with technological media of different densities.

For numerical calculations of hydrodynamics in the apparatus, the Manninen ${ }^{1}$ multiphase model and the standard k-epsilon turbulence model $^{2}$ were used under the condition of the reactor operating in a periodic mode.

Investigations of the distribution of media and flow rates were carried out for a reactor with a volume of $16 \mathrm{~m}^{3}$, the overall dimensions of which are: diameter $2400 \mathrm{~mm}$, height of the cylindrical part $3500 \mathrm{~mm}$. This reactor is equipped with a mixing device and a heat exchanger. The calculations were carried out without taking into account the operation of the heat exchange equipment but taking into account the influence of the heat exchanger design on the mixing process. The research was carried out for a stirrer with stirring speed (n) 420, 720 and $1020 \mathrm{rpm}$. The operating mode of the device is adopted periodic.

The maximum velocity value is observed near the mixer blades for all mixer operating regimes. The low velocity values prevail in the device volume.

\section{References}

1. Manninen M. On the Mixture Model for Multiphase Flow / M. Manninen, V. Taivassalo. - Espoo : Technical Research Center of Finland, VTT Publications, 1996. - 67 p.

2. M. I. Avramenko O k-E modeli turbulentnosti (Preprint Snezhinsk: Izdatelstvo RFYC- VNIITF, 2005, No. 224), pp. 1-21.

